\title{
THE EFFECTIVENESS OF TRAFFICKING IN PERSONS REPORT IN COMBATTING HUMAN TRAFFICKING
}

\author{
Zuraini Ab Hamid ${ }^{1 *}$, Norjihan Ab Aziz $^{2}$, Noor Shuhadawati Mohamad Amin ${ }^{3}$ \\ ${ }^{1}$ Dr., International Islamic University Malaysia, MALAYSIA, zurainihamid@iium.edu.my \\ ${ }^{2}$ Dr., International Islamic University Malaysia, MALAYSIA, norjihanabaziz@iium.edu.my \\ ${ }^{3}$ Mrs., International Islamic University Malaysia, MALAYSIA, shuhadaamin@iium.edu.my \\ ${ }^{*}$ Corresponding Author
}

\begin{abstract}
The Trafficking in Persons (TIP) Report is the main reference for countries around the world, particularly the United Nation state members, in determining their success in combatting human trafficking issues. The objective of the report is to fulfil three principal goals, namely to protect the trafficking victim, to prevent the crime, and to bring the perpetrator to justice. This report was initiated by the U.S. Department of State in 2001 as one of the efforts to monitor and increase worldwide efforts regarding the issues. As a destination and transit country for human trafficking, the U.S. Department of State has become the self-appointed country monitoring the human trafficking progress of (187) state governments since 2004. The first report for human trafficking that was published in 2001 stated that the related countries will be examined and placed either in Tier 1, Tier 2, or Tier 3 depending on their status. In order to be placed in the Tier 1 level, the government must fully comply with the minimum standards outlined in Section 108 of the Trafficking Victims Protection Act of 2000. If the government does not fully comply with the minimum standards for the elimination of trafficking, but has put significant efforts to comply with the standards, it is then placed in Tier 2. The failure for compliance by any governments would place it in Tier 3. Nevertheless, few issues are detected on the effectiveness of the TIP Report in the assessment of a country's achievement in combatting the crime. The issues raised include (i) the monitoring body which is led by the U.S. Department of State; (ii) the 3P paradigm outlined by the Protocol to Prevent, Suppress, and Punish Trafficking in Persons Especially Women and Children which is heeded by the U.S. Department of State; and (iii) the assessment stipulated in the TIP Report which focuses too heavily on the protection of victims. To that end, this article studies the effectiveness of the TIP Report in assessing the countries involved, particularly Malaysia. Combining content analysis and semi-structured interview, this article argues that a lot of improvement must be done on the report's transparency in assessing the countries and thus, proving its effectiveness in combatting the human trafficking issues.
\end{abstract}

Keywords: Human trafficking, Trafficking in Persons, effectiveness, Malaysia.

\section{INTRODUCTION}

The TIP Report has become one of the main sources of reference by foreign governments and organisations for getting updated and reliable information regarding the human trafficking crime. It was initiated by the U.S. Department of State as one of the efforts to combat human trafficking. Initially, trafficking of women and girls 
for sexual purposes is the main concern of the report. After a few years, the U.S. embassies worldwide extended the monitoring to trafficking of men, women, and children for forced labour and commercial sexual exploitation which are the largest forms of trafficking in the world.

The first report of human trafficking was published in 2001. In this report, many countries including Australia were not listed because information was scarcely available. Furthermore, approximately (186) U.S. Department embassies and consulates around the world were involved in the process of completing this report. Trafficking issues and the efforts taken by the host countries of these embassies were noted and presented. The department also reviewed information from other sources such as the United Nations High Commissioner for Refugees (UNHCR), the United Nations Children's Fund (UNICEF), and the media reports.

Notably, Tier 1 is the highest ranking given in the report. Nevertheless, being in Tier 1 does not mean that a country is free from the human trafficking problem. It is merely an indication that the government has acknowledged efforts against the trafficking crime, exerted efforts to curb the problem, and complied with the minimum standards of the Trafficking Victims Protection Act (TVPA). In order to maintain its position in Tier 1 , the state government must show that it has made progress in fighting the crime.

The TIP Report in 2001 listed only twelve countries in Tier 1 as they satisfied the minimum standards in preventing human trafficking. This number has been increasing over the years. In 2016, (36) countries managed to be listed in Tier 1 .

\section{TRAFFICKING IN PERSONS REPORT}

All countries in the report are evaluated, graded, and eventually listed under Tier 1, Tier 2, and Tier 3, respectively. The U.S. Department of State listed all of the evaluation criteria for a country to be placed under the respective tiers. The report explained that the tier of a country depends on the status and achievements of its government in combatting the human trafficking issues. This assessment is performed twice on an annual basis: the first is in June and followed by December. The three tiers are defined as follows:

\section{i) TIER 1}

Countries with its governments fully comply with the TVPA's minimum standards.

ii) TIER 2

Countries with its governments do not fully comply with the TVPA's minimum standards, but are making significant efforts to comply with those standards.

\section{TIER 2 WATCH LIST}

Countries whose governments do not fully comply with the TVPA's minimum standards, but are making significant efforts to bring themselves into compliance with those standards and:

a) The absolute number of victims of severe forms of trafficking is very significant or is significantly increasing;

b) There is a failure to provide evidence of increasing efforts to combat the severe forms of trafficking in persons from the previous year; or

c) The determination of a country in making significant efforts to bring itself into compliance with minimum standards that is based on its commitments to take additional future steps within the next year.

iii) TIER 3

Countries with its governments do not fully comply with the minimum standards and are not making any significant efforts to do so.

Furthermore, TVPA 2008 stated that any country that had been ranked in Tier 2 Watch List for two consecutive years and would be ranked in the same tier in the next year will instead be ranked as Tier 3 . Notably, countries listed in Tier 3 may be subject to certain sanctions including to face opposition from the United States in obtaining support from financial institutions such as the World Bank and the International Monetary Fund. The US government may withhold or withdraw non-humanitarian and non-trade-related foreign assistance. In addition, the countries may not receive funding for the participation of government employees in educational and cultural exchange programs.

In order for a country to be listed in Tier 1 under the TIP Report, it must comply with the minimum standards stated in Section 108 of TVPA 2000. The Act is a guideline to achieve the minimum standards in eliminating 
trafficking and is applicable to the government of a country of origin, transit country, or destination country. The latest TIP Report in 2016 disclosed that the tier rankings and narratives of the countries in the year are based on the following assessments:

i) The enactment of laws prohibiting severe forms of trafficking in persons, as defined by the TVPA, and provision of criminal punishments for trafficking offenses;

ii) The criminal penalties prescribed for human trafficking offenses with a maximum of at least four years deprivation of liberty or a more severe penalty;

iii) The implementation of human trafficking laws through vigorous prosecution of the prevalent forms of trafficking in the country and sentencing of offenders;

iv) The proactive victim identification measures with systematic procedures to guide law enforcement and other government-supported front-line responders in the process of victim identification;

v) The government funding and partnerships with NGOs to provide victims with access to primary health care, counselling, and shelter, allowing them to recount their trafficking experiences to trained social counsellors and law enforcement in an environment of minimal pressure;

vi) The victim protection efforts that include access to services and shelter without detention and with legal alternatives to removal to countries in which victims would face retribution or hardship;

vii) The extent to which a government ensures victims are provided with legal and other assistance and that, consistent with domestic law, proceedings are not prejudicial to victims' rights, dignity, or psychological well-being;

viii) The extent to which a government ensures the safe, humane, and to the extent possible, voluntary repatriation and reintegration of victims; and

ix) The governmental measures to prevent human trafficking, including efforts to curb practices identified as contributing factors to human trafficking, such as employers' confiscation of foreign workers' passports and allowing labour recruiters to charge prospective migrants excessive fees.

x) Government efforts to reduce the demand for commercial sex acts and international sex tourism.

Similar to the earlier TIP Reports, the ten criteria outlined in the 2016 TIP Report depicts that it is mainly focused on the protection of victims. Even though the last criteria was only added recently in 2016, it is also concerned on protecting victims from being sexually trafficked. This crime was significant as it was one of the largest forms of trafficking together with forced labour. A country is in a good position if it ensures that the trafficking victim has been given adequate protection through the prosecution of the trafficker and prevention of the crime.

\section{ISSUES RELATED TO TRAFFICKING IN PERSONS REPORT}

Few issues arise on the efficiency of the TIP Report in assessing a country's achievement in combatting the human trafficking crime. Firstly, the report has received scepticism over its effectiveness to change policy. Moreover, it has been criticised for its determination of tier ranking which is heavily political in nature and its biased justification in the assessment of the narrative countries using $3 \mathrm{P}$ paradigm. Apart from that, this paper also discusses several other issues that are raised by other organisations and countries in the TIP Report, particularly Malaysia.

\subsection{U.S. Department of State}

The first issue is the monitoring body of the report: the U.S. Department of State. Notably, the U.S. has appointed itself as the watcholog country to monitor the UN state members in combatting the human trafficking crime. The introduction of TVPA further established the Office to Monitor and Combat TIPs within the country and required it to provide a summary of anti-trafficking efforts made by foreign governments. This appointment was done via the country's position and authority in the fields of politics, military, and economy.

Apart from providing power to the U.S. to appoint itself as the judge in the placement of countries in the TIP Report, the position also allows the country to make decisions on the issue and to make related rulings. Furthermore, the most significant power owned by the U.S. is to give sanction to a country that is listed 
under Tier 3 of the TIP. The sanction imposed by the Act can only be relinquished partially or totally if the President of the U.S. is satisfied that the assistance to the related government will uphold the purpose of the statute, will benefit the U.S. government, or will avoid adverse effect on the vulnerable citizens.

Other than the President, the Secretary of State also has the power to relinquish the automatic downgrade provided that the country affected must provide authentic evidence showing its government has a good written plan which will facilitate the compliance of the minimum standards set by TVPA upon its execution. To date, no authorised body has been appointed to monitor all the authorities granted to these personnel. In addition, no authentic source has been transparent about the execution of their powers.

For example, TVPA 2008 held that any country that has been ranked in the Tier 2 Watch List for two consecutive years and is going to be ranked in the same category in the subsequent year will instead be ranked in Tier 3 and may be subjected to certain sanctions. Nevertheless, the records proved that this threat is merely written on paper and the U.S. Department of State has the power to not comply with it. This is evident with China that remained in the Tier 2 Watch List for eight years prior to be downgraded to Tier 3 only recently in 2013.

\subsection{P Paradigm Outlined by the Protocol to Prevent, Suppress, and Punish Trafficking in Persons Especially Women and Children}

The second issue is related to the 3P paradigm outlined by the Protocol to Prevent, Suppress, and Punish Trafficking in Persons Especially Women and Children (hereafter referred to as TIP Protocol). It supplements the UNCTOC and is a legally binding global instrument on the signatory countries that defines trafficking in persons. The growing concern on the human trafficking issues at the global level prompted the United Nations to introduce the 3P paradigm through the TIP Protocol that can guide the state parties in combatting human trafficking. Notably, this paradigm is also known as the 3P model, 3P approach, or 3P principle. The $3 \mathrm{P}$ paradigm focuses on the prevention of human trafficking, protection of the trafficking victim, and prosecution of the perpetrator.

Basically, the second approach on protection of the victim is left to the discretion of the state parties. They may choose how to support and assist the victims with the guidance of other international frameworks. No compulsory enforcement regarding this approach is imposed on the UN state parties. Nonetheless, the reality is different and misleading as the protocol outlined is taken very seriously by the U.S. Department of State.

The 3P paradigm provides the main guideline to the TIP Report in assessing a country. In TIP Report 2015, the assessment stipulated for the tier rankings and narratives of the countries is mainly focused on the victims as depicted by six out of nine elements in the document. This portrayed that the protection of the victims must be in accordance with the international and the U.S. practices. An additional element was added in 2016 but it also emphasises on the protection of the victim. Failure to comply with the assessment will cause a country to be ranked at a lower tier and be subjected to sanctions.

Malaysia has not ratified or become an accession party to all the documents and protocols that directly govern the issues of human trafficking, including the TIP Protocol. Therefore, no obligation is imposed on Malaysia to comply with the protocol. Unfortunately, Malaysia was still downgraded to Tier 3 in TIP Report 2014 mainly because of its ineffectiveness in protecting the trafficking victims. The subsequent reports in 2015 and 2016 also disclosed the same reason despite Malaysia's upgrade to Tier 2 . This illustrates that a country's status of ratification on the TIP Protocol and the existence of its own approach in protecting the victim are insignificant. Every country must still be in compliance with the protocol, other international legal frameworks, and the U.S. standards.

Notably, the protection of the victims and their rights are fundamental. Nevertheless, imbalanced concern on the issue will not curtail the crime and accordingly, no stringent formula may solve the human trafficking issues. Sole dependency on legal approaches narrows the efforts and their effectiveness. Thus, it is vital to develop appropriate measures and effective strategies that combine and balance all the possible approaches to ensure the success of this effort.

Furthermore, the TIP Report should also consider the capability of the state members in complying with the 3P paradigm. The U.S. Department of State and the TIP Report seem to grade all countries in the same position regardless of the country's economy, resources, and capabilities. For instance, Australia is a developed country which is different from developing countries like Thailand and Malaysia. As a developed country, Australia has adequate resources, strong economy, capabilities, and advantages to curb the issues of human trafficking. At the same time, the country also has enough financial resources to provide protection 
for the victims as required by the international legal framework. Its financial capability is sufficient to handle the issues in their countries, as well as other countries.

For example, Australia had outsourced foreign migrants and potential trafficking victims to Papua New Guinea as a return for the financial help given to the country. Malaysia had also received a ship and boat from Australia for the Malaysian Maritime Enforcement Agency for stopping the criminal activities at sea, especially the smuggling of migrants into Australia. These actions may hardly be followed by poor countries such as India and Indonesia or by developing countries like Thailand and Malaysia. Therefore, the U.S. Department of State and the TIP Report should have different guidelines and mechanisms in assessing the state members based on their capability and resources.

To that end, the entire 3P paradigm should be given a fair and thorough consideration, particularly on the prevention of the human trafficking crime. Too many programs and efforts are taken to secure the needs and provide aid to the victims without giving adequate attention to prevent the crime itself. The idiom prevention is better than cure which means that it is better to avoid something bad from happening rather than to deal with it after its occurrence, is appropriate for this scenario. It would be fruitless to provide a lot of shelters for the victims, permits for their stay, or financial assistance if the victims themselves remain exposed to the crime and are willing to be exploited.

The prevention of human trafficking can be done by educating the public, especially the vulnerable victims, starting from their countries of origin. The laws in the origin, transit, and destination countries must be able to prevent the victims from being exploited. It is essential for the country of origin to set strict laws for its citizens before they are allowed to travel outside the country. In addition, the transit or destination country must impose strict laws before allowing a foreign citizen to enter or remain in the country. All of these related countries should share the same responsibility and liability on the matter. If the protection of the victims in the transit or destination country is the only focus of the TIP Report, the report is deemed as biased.

\subsection{Ambiguity of TIP Assessment}

The assessment carried out by the U.S. Department of State in ranking the tier of the countries is also ambiguous. Even though a guideline for the assessment exists, no data proved their compliance to the guideline in determining whether a country has fulfilled the requirements. For example, the 2012 TIP Report claimed that the enforcement bodies in Malaysia were ineffective and few government officers were involved in the trafficking activities. Moreover, the Malaysian government was also accused of being ignorant in conducting the investigation or in taking action against the corrupt officers.

Nonetheless, no data, evidence, police report, or official report made by any complainant regarding this matter was present. The TIP Report should have firm basis and concrete evidence in declaring such statements rather than relying on unfounded information. Ideally, they may cooperate with the Malaysian government to obtain accurate information from the relevant Malaysian bodies.

In the past, the Malaysian government had carried out an investigation on an immigration officer who was arrested in July 2009 for an alleged involvement in the trafficking of Burmese citizens to Thailand. Nonetheless, the case was ended in an acquittal as the officer was found to be not guilty. This example demonstrates that Malaysia is serious in taking action against its officers. Accordingly, the U.S. Department of State and the TIP Report must be transparent in making their assessment, where the state members must be given the right to know the basis of their ranking.

Apart from that, the countries must also be given the rights to appeal or request for an explanation if they are not satisfied with the report. They should have the rights to defend their countries as the tier ranking will tarnish their global image. To date, no guidelines and rights are stipulated to guide the countries in responding if they are unsatisfied with the report. In the absence of such guidelines, the Malaysia Council for Anti-Trafficking in Persons and Anti-Smuggling of Migrant or Majlis Antipemerdagangan Orang (MAPO) explained that countries like Malaysia and Thailand had submitted letters to the U.S. Embassy to express their dissatisfaction on the TIP Report. These countries believed that the report was generated on hearsay basis. Unfortunately, they did not receive any positive responses on the letters.

Furthermore, the U.S. Governmental Accountability Office reported that the TIP Reports do not provide a full description on the compliance of each country with the minimal standards. On the contrary, in particular cases like prosecution for sexual exploitation, comprehensive explanation was provided on only few countries. The failure of the report in providing full description for all countries involved may cause the assessment to be doubted as the basis of evaluation is unclear. 


\section{CONCLUSION}

The introduction of the TIP Report as a monitory tool for international protocols and conventions has strengthened the foundation as the state members are guided in formulating their domestic laws against human trafficking. Regrettably, their effectiveness is still doubted when the U.S. Department of State as the monitoring country did not disclose the process of the assessment in a transparent manner. The UN state members are sceptical on the considerations and evidences that were applied in the assessment.

Furthermore, it is very unlikely that they have the capability in objecting to the assessment, since the UN remains silent on the matter. They have been accepting the TIP Report continuously without approaching the proper channel to voice out their opinion or dissatisfaction. If this situation persists, no positive changes may be seen regarding the position of the countries in the TIP Report, regardless of whether or not the country has ratified the TIP Protocol or the convention.

Moreover, the ten requirements outlined by the TIP Report may not facilitate the countries in preventing the crime but may cause them further hardship due to their incapability to strictly adhere to the requirements. This is especially in the absence of strong economy, politics, and social foundation to support the efforts of these countries. Plus, the struggle of the state members in applying the 3P paradigm merely for the sake of the TIP Report is not an effective approach without an understanding on the prevalence of human trafficking at the specific countries. Thus, the TIP Report should be further interpreted and re-evaluated by the U.S. Department of State to ensure its effectiveness as a monitoring tool for the countries around the world on the human trafficking issues.

\section{ACKNOWLEDGEMENT}

This research was financially supported by the International Islamic University Malaysia Research Initiative Grant Scheme (RIGS16-058-0222).

\section{REFERENCE LIST}

Alese Wooditch. (2011). The Efficacy of the Trafficking in Persons Report: A Review of the Evidence, Criminal Justice Policy Review, 22(4): 471-493

Anonymous, Interviewed by Author, Malacca, 4 September 2013. She is a government legal officer at Papua New Guinea. The statement made based on her opinion and not represent the government of Papua New Guinea.

Anonymous, Interviewed by Author, Majlis Anti-Pemerdagangan Orang's Office, 24 October 2014.

Anonymous, Interviewed by Author, Malaysian Maritime Enforcement Agency, Putrajaya, 28 February 2014.

Anti-Trafficking In Persons and Anti-Smuggling of Migrants Act 2007 (Act 670).

Bales, K. (2012). Disposable people: New slavery in the global economy. Oakland: University of California Press.

Cambridge Advanced Learners Dictionary \& Thesaurus; Cambridge University Press, see also http://dictionary.cambridge.org/dictionary/british/prevention-is-better-than-cure.

Country Narratives, Trafficking in Persons Report July 2001, U.S. Department of State, <http://www.state.gov/j/ tip/rls/tiprpt/2001/3927.htm> (accessed 3 January, 2013)

Ebbe, O. N. (2008). Causes of trafficking in women and children. In O. N. Ebbe, \& D. K. Das (Eds.), Global trafficking in women and children (pp. 33-38). Boca Raton, FL: CRC Press.

Einstein, A. (1916). General Theory of Relativity. Annalen der Physik, 49 (7).

Fredette, K. (2009). Revisiting the UN Protocol on Human Trafficking: Stricking the Balances for More Effective Legislation. 17 Cardozo Journal of International and Comparative Law 101, 103.

Gallagher, A. (2006). Human rights and human trafficking in Thailand: A shadow TIP report. In K. D. Beeks \& D. Amir (Eds.), Trafficking and the global sex industry (pp. 139-164). Lanham, MD: Lexington Books.

Introduction Trafficking in Persons Report July 2001, U.S. Department of State, <http://www.state.gov/j/tip/rls/ tiprpt/2001/3929.htm> (accessed 3 January, 2013). 
Pemerdagangan Orang: Pegawai Imigresen Kekal Bebas, Sinar Harian, <http://www.sinarharian. com.my/pemerdagangan-orang-pegawai-imigresen-kekal-bebas-1.175683> (accessed 10 December 2015).

Sanja Milivojevic and Marie Segrave, in Responses to sex trafficking: gender, boarder and home, edited by Leslie Holmes (UK: Edward Elgar Publishing Ltd, 2010), 45.

Secretary Clinton to Release Annual Trafficking in Persons (TIP) Report, Washington, DC, <http://www.state.gov/r/pa/prs/ps/2012/06/193219.htm> (accessed 3 January, 2015).

The 2011 TIP Report: Methodology Trafficking in Persons Report 2011 U.S Department of State's, <http://www.state.gov/j/tip/rls/tiprpt/2011/164222.htm> (accessed 20 March, 2015).

The Developing Countries, The International Statistical Institute, <http://www.isi-web. org/component/content/article/5-root/root/81-developing> (accessed 4 December, 2015).

The Poorest Countries in the World, Global Finance, <https://www.gfmag.com/global-data/economicdata/the-poorest-countries-in-the-world> (accessed 4 February, 2016).

Tier Placements- Trafficking In Persons Report 2013, U.S. Department of State, <http://www.state.gov/j/tip/rls/tiprpt/2013/210548.htm> (accessed 19 May, 2016).

Tier Placements, Office to Monitor and Combat Trafficking in Persons, Trafficking in Persons Report 2012, U.S. Department of State, <http://www.state.gov/j/tip/rls/tiprpt/2012/192363.htm> (accessed 3 January, 2015).

Trafficking in Persons 2014 Report: Country Narratives, U.S Department of State, $<$ http://www.state.gov/j/tip/rls/tiprpt/countries/2014/index.htm> (accessed 3 June, 2016).

Trafficking in Persons Report 2012 U. S. Department of State, <http://www.state.gov/j/tip/rls/tiprpt/2012/192367.htm> (accessed 5 December, 2015).

Trafficking in Persons Report July 2015, U.S Department of State, accessed Dec 10, 2016, https://www.state.gov/documents/organization/258876.pdf

Trafficking in Persons Report June 2014, U.S Department of State. <http://www.state.gov/ documents/organisation/226847.pdf> (accessed on 27 June, 2015).

Trafficking in Persons Report, U.S Department of State, <http://www.state.gov/j/tip/rls/tiprpt/> (accessed 3 January, 2015).

Trafficking in Persons Report July 2016, US Department of State, https://www.state.gov/documents/organization/258880.pdf (accessed 14 December, 2016)

Trafficking Victims Protection Act, 2000 (Div. A of Pub. L. No. 106-386)

Trafficking Victims Protection Reauthorization Act of 2008

U.S. Congress, House of Representatives, House Committee on International Relations. (2002, June 19). Foreign Government Complicity in Human Trafficking: A Review of the State Department's 2002 Trafficking in Persons Report. Testimony, Donna M. Hughes, Professor, University of Rhode Island, Kingston.

United Nations General Assembly. (1995a). Implementation of General Assembly Resolution 49/150 on the Naples Political Declaration and Global Action Plan against Organized Transnational Crime (A/50/433). New York: Author. 